\title{
Comparison of News Impacts on Sectoral Stock Returns during the COVID-19 Pandemic in Turkey
}

\author{
Metin TetiK
}

Received: 05.06.2021; Revised: 21.08.2021; Accepted: 26.10.2021

\begin{abstract}
This study examines how the volatility of the sectoral stock returns within Borsa Istanbul are affected during the COVID-19 pandemic. The analysis uses daily stock return data for four main sector indices: services, finance, industry, and technology. The sample period of the study covers 03.03.2015-11.03.2021, and 12.03.202003.04.2021 is separately analyzed for the COVID-19 period. When E-GARCH models and news impact curves are analyzed, it is found that the services sector stock returns volatility differs from other sectoral stock returns.
\end{abstract}

JEL codes: C58, G14, E44

Keywords: COVID-19, Stock returns, Investment decisions, E-GARCH model

\section{Introduction}

The coronavirus (COVID-19) epidemic emerged in Wuhan, China in December 2019, and then became a global pandemic. The COVID-19 pandemic has spread to 215 countries. As of November 2021, it caused about 246 million cases and more than 5 million deaths. In addition, the pandemic led to a limitation of human mobility due to public health controls, supply chains are disrupted and reduced activities in the manufacturing and services sectors has created a major economic recession all over the world. Moreover, stock markets have crashed worldwide, and the number of unemployment claims has risen to unprecedented levels (Elgin et al., 2020). In addition, some sectors, such as the medical products and pharmacy sector, food sector, and video streaming, have turned this situation into an opportunity. Therefore, the COVID-19 outbreak did not affect businesses at the same level at the sectoral level. Hence, financial investors' demand for stocks of enterprises at the sectoral level may be affected by the COVID-19 outbreak (Özdemir, 2020).

This study focuses on the differences in the return behavior of four Borsa Istanbul (BIST) sectoral indices (financial index, services index, industrial index, and technology index). By examining the data at a daily frequency, we analyse how the volatility of the BIST sector index returns react to good and bad news and compare how each sector reacts to the news. We use the exponential generalized autoregressive conditional heteroscedasticity (E-GARCH) model to estimate the conditional (or short-run) variance of sectoral stock

a Department of Logistic Management. Applied Sciences Faculty. Uşak University. email: metin.tetik@usak.edu.tr (D) https://orcid.org/0000-0003-2741-7175 
price returns. Engle (1982) shows that allowing time-varying fluctuations can improve the estimation of the studied series and provide useful information for financial decisionmaking. In light of Engle \& Ng (1993)'s well-known finding that stock market returns respond to "bad" news rather than "good" news, we examine whether BIST sectoral returns respond asymmetrically to the shocks in different nature. The results of the E-GARCH $(1,1)$ model show that, during the COVID-19 period, negative shocks created more volatility than positive shocks for the sectoral return of services, whereas negative shocks created less volatility than positive shocks for the other sectors. We also find out that the responses of the finance and service sectors to the news are symmetrical, while the industry and technology stocks display asymmetrical responses through the news impact curves.

The rest of the paper is organized as follows. The next section presents the existing literature on the relationship between COVID-19 and stocks return. Section 3 gives detailed information about the estimated model and methodology utilized in this paper. The data and empirical findings are discussed in Section 4, and finally, the conclusions are presented in Section 5.

\section{Related Literature}

In this section, the studies examining the impacts of the COVID-19 pandemic on the stock markets in Turkey are summarised, and the prominent studies are evaluated. Göker et al. (2020) conducted case studies for 26 sectors in the BIST and found that most of the sectors had negative Cumulative Average Extraordinary Returns (CAER) during most of the period examined, while the CAER values of different sectors were positive in some periods. Although the rates vary according to different event windows, it was determined that the highest loss is in the sports, tourism, and transportation sectors. Özdemir (2020) examined the asymmetrical relationship between the number of COVID-19 cases and deaths and the sector indices with the Hatemi-J asymmetric causality test. As a result of the test, it was determined that the positive shocks in the number of COVID-19 cases and deaths differed from the shocks on sectoral returns. Similarly, Öztürk et al. (2020) investigated the impacts of the COVID-19 outbreak on the sectors in Borsa Istanbul and concluded that the pandemic harmed almost all sectors. On average, three main sectors (industry, services, and finance) were affected almost equally, but there are differences at the level of sub-sectors. Especially metal products, machinery, sports, tourism, transportation, banking, and insurance sectors are among the most affected sectors. On the other hand, food, beverage, wholesale and retail trade were identified as less affected sectors. Tayar et al. (2020) applied a simple linear regression analysis using the daily change in the number of cases in Turkey and the daily change in the BIST sector indices. As a result of the analysis, it has been determined that the COVID-19 outbreak has significant and negative impacts on the electricity, transportation, financial, industrial, and technology indices. Kılıç (2020) used the case study method concluded that the COVID-19 outbreak harmed the BIST sector index returns in general. While it was determined that the textile and tourism sectors were exposed to the highest negative impact, it was concluded that the trade sector provided positive returns during the pandemic process.

On the other hand, there are many studies in the literature examining the impact of the COVID-19 pandemic on financial markets in different countries (Sansa, 2020; Zhang et al., 2020; Liu et al., 2020; Zeren \& Hizarc1, 2020; Ashraf, 2020). These studies mostly 
examine the relationship between the number of COVID-19 cases/deaths and stock returns and generally conclude that there is a negative and significant relationship. However, there is also evidence to the contrary (Al-Awadhi et al., 2020).

Although this study is similar in general to the studies mentioned in the related literature, it differs in terms of empirical analysis. First of all, almost all of the studies mentioned directly added the number of cases and deaths in the COVID-19 period to their models and accepted the accuracy of these numbers. Moreover, I think that associating stock returns directly with the number of cases and deaths is a limited consideration, both empirically and theoretically. From a finance theory point of view, it is a bit of a hassle to explain/relate the price of stock directly to the number of deaths. Although the number of deaths may negatively affect economic prospects, treating it as the direct and sole cause of stock prices can create problems for analysis. In addition, it is known that the number of cases and deaths is controversial within the framework of the Turkish sample. As a matter of fact, in December 2020, the case definition was changed, and more realistic data began to be announced. Case and death numbers were not used in this study. The positive and bad news that emerged during the COVID-19 period was determined internally by the model. Thus, this method is considered to be more reliable.

\section{Methodology}

This study examines how the news affects the investment in sectoral stocks during the COVID-19 period. We use an E-GARCH model to estimate the conditional (or short-term) variance of industry stock price returns. In ARCH and GARCH models, the shock signs disappear as the errors are squared. Only their size can be interpreted. In other words, the impact of positive shocks and negative shocks on volatility is calculated as the same in the model. This situation does not fully reflect a reality that exists in financial asset price series. The expected situation is that a negative shock of the same size (bad news) has a greater impact on volatility than a positive shock (good news). Such asymmetric stock returns are called the leverage effects. The decline in the firm's stock will cause an increase in the debtequity ratio. According to Franses et al. (2000), the behavior of the conditional variance of the time series of financial asset prices is generally asymmetric concerning the previous return. In addition, during recession periods, the volatility in the prices of financial assets is at a high level. In short, asymmetric volatility is the characteristic feature of financial time series (Li \& Li, 1996). The most used asymmetrical GARCH models are Threshold ARCH models (TARCH - Threshold ARCH) developed by Zakoian (1994) or the GJR - GARCH model, which is very similar to the TARCH model, of Glosten et al. (1993). E-GARCH (Exponential GARCH) model was developed by Nelson (1991).

The leptokurtic structure and volatility clustering, which exist in financial time series, can be detected effectively with the GARCH model. However, the E-GARCH model was developed to eliminate the weaknesses of the GARCH model by taking into account the asymmetry in the volatility structure since the GARCH model does not provide effective results and fails to capture the asymmetry that serves to distinguish negative and positive shocks in the variance structure. In the E-GARCH model, the possibility that the positive and negative shocks in the financial markets will not have the same impact on the predictability of the future volatility of financial assets is taken into account. A positive shock has less impact on volatility than a negative shock. That is, financial assets series react 
more to bad news. This effect, so-called the "Leverage Effect", was first suggested by Black (1976). This situation, in which it is claimed that bad news in the market has more impact on the volatility of financial assets than a positive one, is modeled as follows:

$$
\ln \left(\sigma_{t}^{2}\right)=\alpha+\gamma\left(\frac{u_{t-1}}{\sigma_{t-1}}\right)+\lambda\left|\frac{u_{t-1}}{\sigma_{t-1}}-\sqrt{\frac{2}{\pi}}\right|+\beta \ln \left(\sigma_{t-1}^{2}\right)
$$

As seen in equation (1), the conditional variance of a time series in the E-GARCH $(1,1)$ model is a nonlinear function of the magnitude and sign of its past values and lagged residuals. The term $\frac{u_{t-1}}{\sigma_{t-1}}$ in the conditional variance equation is the standardized error term. The use of standardized error terms instead of the historical values of the error terms in the E-GARCH model provides information about the magnitude and persistence of the shock. Concerning the $\gamma$ parameter in the conditional variance equation, the term $\frac{u_{t-1}}{\sigma_{t-1}}$ gives the E-GARCH model an asymmetrical character. The $\gamma$ parameter is the asymmetric leverage coefficient that defines the "Leverage Effect" in volatility. The most important sign that this model works is that the $\gamma$ parameter is statistically significant. Accordingly, the statistically significant negative $\gamma$ parameter shows that negative shocks generate more volatility than positive shocks. On the other hand, the positive $\gamma$ parameter, which is significant, indicates that positive shocks generate more volatility than negative shocks.

If we consider $u_{t-1}=0$ as the smallest value of the news impact curves based on the E-GARCH models, both ends of the curve expand in both directions exponentially but depending on different parameters. The news impact curves are generated using the coefficient estimates of the lagged conditional variance from the estimated unconditional variance equations of the relevant models. Considering equation (1); the news impact curve is defined as:

$$
\begin{gathered}
\sigma^{t}=\left\{\begin{array}{c}
A \exp \left|\frac{\gamma+\lambda}{\sigma_{t}}\right| \Longrightarrow u_{t-1}>0 \\
A \exp \left|\frac{\gamma+\lambda}{\sigma_{t}}\right| \Longrightarrow u_{t-1}<0
\end{array}\right\} \\
A=\sigma_{t}^{2 \beta} \exp \left(\alpha-\lambda \sqrt{\frac{2}{\pi}}\right)
\end{gathered}
$$

An important determinant of asset prices is that "bad" news has greater and more permanent impact on volatility than "good" news. Many of the shocks have a negative correlation with the future volatility level and the present return. In this context, we can define the leverage effect as the notion that volatility tends to decrease when returns increase and tend to increase when returns decrease. The main idea of the leverage effect is defined as the magnitude of "new information" $u_{t-1}$ and is measured in this way. If $u_{t-1}=0$, it means that the expected volatility $\left(\sigma_{t}\right)$ is constant. On the other hand, if $u_{t-1}$ is positive (i.e., the news is "good"), volatility is expected to increase given that the leverage/sign effect $(\gamma)$ is negative but the size of shock $(\lambda)$ dominates, or $(\gamma)$ is positive. If the news is "bad", both the leverage/sign and the size of the shock will boost volatility further. Therefore, we conclude that the impact of a positive shock $\left(u_{t-1}\right)$ on volatility will be lower and more temporary than a negative shock. Asymmetric volatility modeling is an approach that attracts a lot of attention in the literature, as good and bad news have different impacts on the models created to predict future volatility. As Chen \& Ghysels (2011) stated in their findings, while good news has a reducing impact on volatility in intraday trading, very good news and bad 
news increase volatility.

\section{Data and Results}

BIST includes daily stock return data based on four main sectors: services sector, financial sector, industrial sector and technology sector. The whole sample covers the period of 03.03.2015-11.03.2021, whereas the period of 12.03.2020-03.04.2021 is separately analyzed as the COVID-19 period. The data for all assets are retrieved from Investing.com. The observed return series to be used in forecasts is calculated as follows.

$$
R_{t}=\frac{\left(P_{t}-P_{t-1}\right)}{P_{t-1}} x 100
$$

where, $P_{t}$ is the stock prices on day $t, R_{t}$ is the stock return on day $t$. The graph of the price and return series is given in Figure 1.
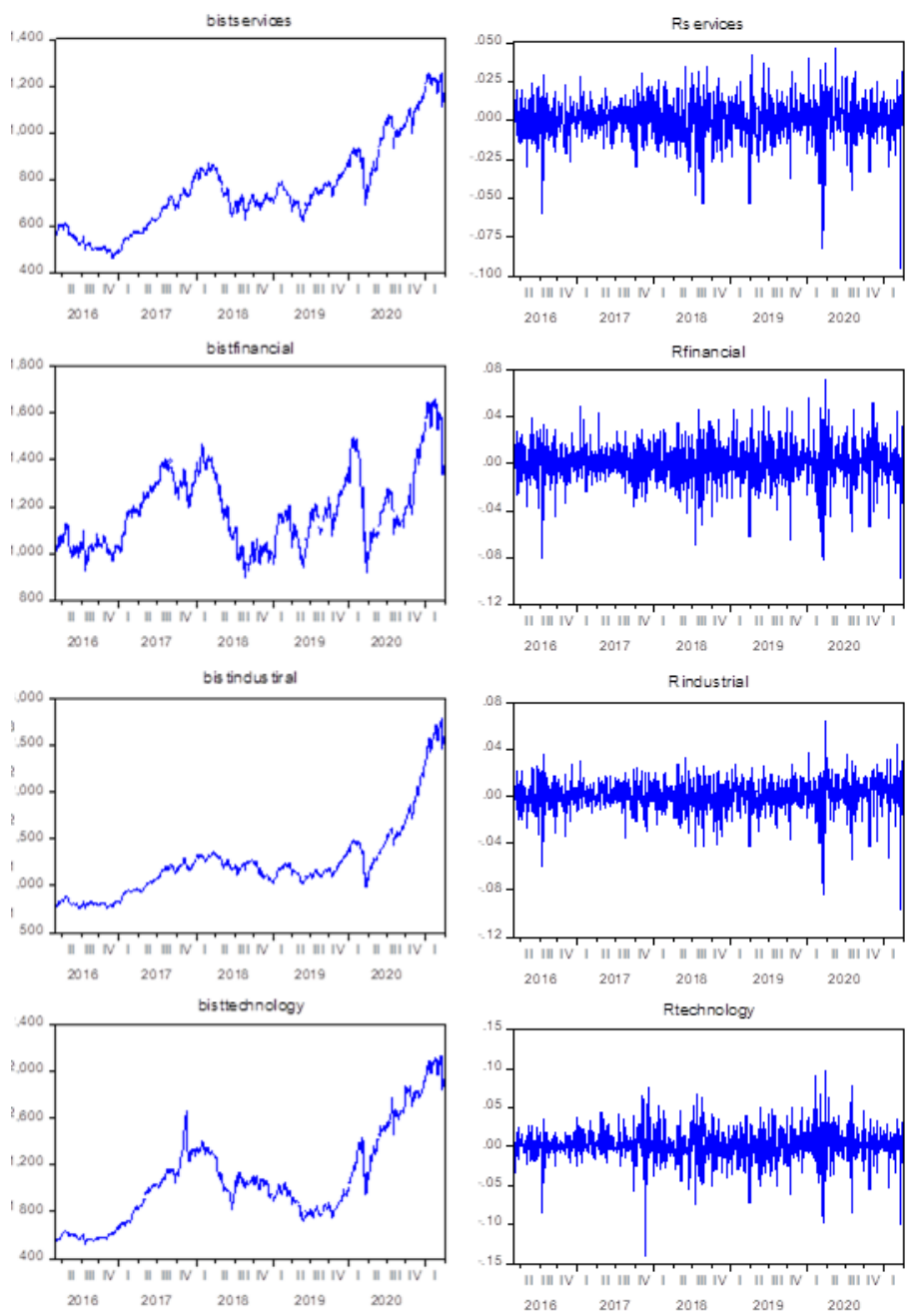

Figure 1: Sectoral Stock Price (left) and Return Series (right) 
Table 1: Descriptive statistics

\begin{tabular}{ccccc}
\hline & $R_{\text {services }}$ & $R_{\text {financial }}$ & $R_{\text {industial }}$ & $R_{\text {technology }}$ \\
\hline Mean & 0.000675 & 0.000389 & 0.001051 & 0.001156 \\
Std. Dev. & 0.012903 & 0.016656 & 0.013055 & 0.019589 \\
Skewness & -0.994134 & -0.529286 & -1.098401 & -0.554140 \\
Kurtosis & 8.593554 & 6.450771 & 9.150969 & 8.851222 \\
Jarque-Bera & 1876.586 & 693.7622 & 2271.664 & 1888.515 \\
Probability & 0.000000 & 0.000000 & 0.000000 & 0.000000 \\
Observations & 1278 & 1278 & 1278 & 1278 \\
\hline
\end{tabular}

Descriptive statistics for the entire period on the stock returns are given in Table 1. It is evident that the returns of all series are negatively skewed, and the kurtosis is well above 3 for all cases. This is an indication of the deviation of the series from the normal distribution, which is also supported by Jarque-Bera statistics. In addition, the stationarities of the variables are examined using Augmented Dickey-Fuller (ADF-Dickey \& Fuller (1981)), Phillips-Perron (PP-Phillips \& Perron (1988)), and Kwiatkowski, Phillips, Schmidt, and Shin (KPSS-Kwiatkowski et al. (1992)) unit root tests. The test results are provided in Table 2.

Table 2: Linear Unit Root Test

\begin{tabular}{lllc}
\hline & ADF Test & PP Test & KPSS Test \\
\hline$R_{\text {services }}$ & $-33.186^{* * *}$ & $-33.197^{* * *}$ & 0.102 \\
$R_{\text {financial }}$ & $-35.686^{* * *}$ & $-35.686^{* * *}$ & 0.048 \\
$R_{\text {industial }}$ & $-22.686^{* * *}$ & $-34.739^{* * *}$ & 0.281 \\
$R_{\text {technology }}$ & $-35.397^{* * *}$ & $-35.386^{* * *}$ & 0.130 \\
\hline Unit root testing is only performed on intercept. It is no need \\
to include the trend in the unit root equation due to detrended \\
by taking the first difference, already. \\
The lag length for the ADF test is chosen based on the SIC \\
criterion. The PP and KPSS tests are estimated on the basis \\
of the Bartlett-kernel, by using the Newey-West bandwidth. \\
The null hypothesis of the ADF and PP tests is that the se- \\
ries is nonstationary while the null hypothesis is stationarity \\
against the alternative of a unit root for the KPSS test. ${ }^{* *}$, \\
$* *$ and * indicate statistical significance at the $1 \%, 5 \%$ and \\
$10 \%$ levels, respectively.
\end{tabular}

The results in Table 2 show that all return series are stationary. After performing unit root tests, different versions of E-GARCH models are estimated for all selected sectors for the entire period and the COVID-19 period separately. Table 3 shows the results of the multivariate E-GARCH models.

Other sector stock returns are included in the mean equation of all E-GARCH $(1,1)$ models displayed in Table $3 .{ }^{1}$ It is seen that the coefficients of these variables are positive, i.e., in the expected direction, and statistically significant.

The results obtained from the variance equations of all EGARCH $(1,1)$ models displayed in Table 3 shed light on our research rationality. The size effects $(\lambda)$ in all E-GARCH models are greater in the technology sector than in the other sectors. The parameter $\lambda$ can be thought of as providing insight into how the previous period's shock affects current

1 For instance, mean equation specification for services sector is as follows; $R_{\text {services }}=$ Constant + $R_{\text {financial }}+R_{\text {industrial }}+R_{\text {technology }}+u_{t}$. 
period's volatility. The parameter $\lambda$ is statistically significant during the COVID-19 period

Table 3: E-GARCH Model Results

\begin{tabular}{|c|c|c|c|c|c|c|c|c|}
\hline & \multicolumn{4}{|c|}{ Entire Period } & \multicolumn{4}{|c|}{ COVID-19 Period } \\
\hline & \multicolumn{2}{|c|}{ Mean Equation } & \multicolumn{2}{|c|}{ Variance Equation } & \multicolumn{2}{|c|}{ Mean Equation } & \multicolumn{2}{|c|}{ Variance Equation } \\
\hline & Coefficient & Z Stat & Coefficient & Z Stat & Coefficient & Z Stat & Coefficient & Z Stat \\
\hline \multicolumn{9}{|c|}{ Dependent Variable: $R_{\text {services }}$} \\
\hline Constant & 0.00 & -0.04 & & & & & & \\
\hline$R_{\text {financial }}$ & $0.29 * * *$ & 17.35 & & & $0.23^{* * *}$ & -3.95 & & \\
\hline$R_{\text {industrial }}$ & $0.38 * * *$ & 18.76 & & & $0.43^{* * *}$ & 6.61 & & \\
\hline$R_{\text {technology }}$ & $0.08 * * *$ & 6.44 & & & $0.079 * *$ & 0.89 & & \\
\hline$\alpha$ & & & $-0.53^{* * *}$ & -3.95 & & & $-0.33^{* * *}$ & -13.23 \\
\hline$\gamma$ & & & $0.18^{* * *}$ & 6.61 & & & $-0.13 * * *$ & -4.13 \\
\hline$\lambda$ & & & 0.01 & 0.89 & & & $0.10^{* * *}$ & 4.23 \\
\hline$\beta$ & & & $0.96^{* * *}$ & 76.24 & & & $0.96^{* * *}$ & 5,800 \\
\hline \# of obs. & \multicolumn{4}{|c|}{1,278} & \multicolumn{4}{|c|}{267} \\
\hline$R^{2}$ & \multicolumn{4}{|c|}{0.64} & \multicolumn{4}{|c|}{0.69} \\
\hline D.W Stat. & \multicolumn{4}{|c|}{1.95} & \multicolumn{4}{|c|}{1.9} \\
\hline \multicolumn{9}{|c|}{ Dependent Variable: $R_{\text {financial }}$} \\
\hline Constant & $-0.00^{* * *}$ & -2.96 & & & $-0.00^{* * *}$ & -3.29 & & \\
\hline$R_{\text {services }}$ & $0.44^{* * *}$ & 16.09 & & & $0.43^{* * *}$ & 7.15 & & \\
\hline$R_{\text {industrial }}$ & $0.61 * * *$ & 22.87 & & & $0.50 * * *$ & 8.52 & & \\
\hline$R_{\text {technology }}$ & $0.10^{* * *}$ & 7.31 & & & $0.20 * * *$ & 5.76 & & \\
\hline$\alpha$ & & & $-0.97 * * *$ & -4.86 & & & $-2.53^{* * *}$ & -4.06 \\
\hline$\gamma$ & & & $0.26^{* * *}$ & 8.45 & & & $0.64^{* * *}$ & 5.11 \\
\hline$\lambda$ & & & 0.01 & 0.43 & & & 0.04 & 0.63 \\
\hline$\beta$ & & & $0.92^{* * *}$ & 46.04 & & & $0.78^{* * *}$ & 12.22 \\
\hline \# of obs. & \multicolumn{4}{|c|}{$\begin{array}{c}1,278 \\
0.68\end{array}$} & \multicolumn{4}{|c|}{267} \\
\hline & \multicolumn{4}{|c|}{0.68} & \multicolumn{4}{|c|}{0.70} \\
\hline D.W Stat. & \multicolumn{4}{|c|}{1.94} & & & .75 & \\
\hline & & & $\overline{\text { Dependent }}$ & Variable: & $R_{\text {industrial }}$ & & & \\
\hline Constant & $-0.00 * * *$ & 2.78 & & & $0.00^{* *}$ & 4.11 & & \\
\hline$R_{\text {services }}$ & $0.32 * * *$ & 15.11 & & & $0.35^{* * *}$ & 8.98 & & \\
\hline$R_{\text {financial }}$ & $0.35^{* * *}$ & 21.76 & & & $0.31 * * *$ & 10.04 & & \\
\hline$R_{\text {technology }}$ & $0.11^{* * *}$ & 9.35 & & & $0.21^{* * *}$ & 5.78 & & \\
\hline$\alpha$ & & & $-0.28 * * *$ & -4.70 & & & $-15.94^{* * *}$ & -6.67 \\
\hline$\gamma$ & & & $0.13^{* * *}$ & 7.41 & & & $0.25 *$ & 1.71 \\
\hline$\lambda$ & & & $-0.02 * *$ & -2.01 & & & -0.04 & -0.64 \\
\hline$\beta$ & & & $0.98^{* * *}$ & 180.01 & & & $-0.61 * *$ & -2.42 \\
\hline \# of obs. & & & & 1,278 & & & 267 & \\
\hline$R^{2}$ & & & & 0.68 & & & .80 & \\
\hline D.W Stat. & & & & 1.98 & & & .93 & \\
\hline & & & Dependent V & Tariable: & $R_{\text {technology }}$ & & & \\
\hline Constant & $-0.00 * * *$ & 7.16 & & & 0.00 & 0.02 & & \\
\hline$R_{\text {services }}$ & $0.31^{* * *}$ & 9.09 & & & $0.20^{* *}$ & 2.55 & & \\
\hline$R_{\text {financial }}$ & $0.30 * * *$ & 8.06 & & & $0.31 * * *$ & 5.01 & & \\
\hline$R_{\text {industrial }}$ & $0.38^{* * *}$ & 9.35 & & & $0.51 * * *$ & 5.28 & & \\
\hline$\alpha$ & & & $-0.75^{* * *}$ & -7.40 & & & $-0.88^{* * *}$ & -3.54 \\
\hline$\gamma$ & & & $0.22 * * *$ & 9.16 & & & $0.19^{* * *}$ & 2.80 \\
\hline$\lambda$ & & & $0.07 * * *$ & 5.70 & & & $0.12^{* * *}$ & 3.22 \\
\hline$\beta$ & & & $0.93^{* * *}$ & 88.8 & & & $0.92^{* * *}$ & 34.86 \\
\hline \# of obs. & & & 278 & & & & 267 & \\
\hline & & & 46 & & & & .67 & \\
\hline D.W Stat. & & & 93 & & & & .96 & \\
\hline
\end{tabular}


for the services sector. This shows us that previous shocks to the services sector only affected the current volatility during the COVID-19 period. However, in order to make a clear comment, it is necessary to consider both size and sign effects (Ewing et al., 2005). In all E-GARCH models, sign effect $(\gamma)$ is positive for all sector returns. This means that positive shocks increase volatility more than negative shocks. However, in the COVID-19 period, $\gamma$ is negative only for services sector returns, while it is positive for the other three sectors. In E-GARCH models, conventionally, negative $\gamma$ means negative shocks increase volatility more than positive shocks. Thus, this suggests that negative return shocks generate more volatility than positive return shocks for the services sector returns. Therefore, negative news's impact on the services sector was more significant in the COVID-19 period, compared to the entire sample period. Heterogeneity in returns at the sectoral level is generally in line with the findings of Kandil Göker et al. (2020), Kılıç (2020), and Özdemir (2020). Unlike Öztürk et al. (2020) and Özdemir (2020), it is worth noting that COVID-19-related news differs in affecting services sector returns, but not financial or technology returns. This result can be considered more plausible, especially considering that the sector most affected by the COVID-19 quarantine measures is the services sector.

The news impact curves obtained using the E-GARCH estimation method, which allows asymmetric expectation formation processes, can be seen in Figure 2.

In Figure 2, the news impact curve of E-GARCH $(1,1)$ is compared for all the entire and the COVID-19 periods. The news impact curve of all sectors in the entire period is Ushaped, which implies that greater shocks (whether negative or positive) increase volatility more than smaller shocks. Besides, the news impact curves of services and financial sectors in the entire sample period are nearly symmetrical. In this context, when looking at the entire period, we can say that negative shocks on the returns of the services and financial sectors and positive shocks of the same magnitude affect the future volatility of the sectors in a similar way. On the other hand, the news impact curves of the industrial sector are asymmetrical. Thus, negative shocks on the industrial sector stock returns affect future volatility more than positive shocks of the same magnitude. Similarly, the news impact curves of technology sector returns are asymmetrical. However, positive shocks in this sector seem to affect future volatility more than negative shocks of the same magnitude in comparison with industrial sector stock returns.

When we look at the news impact curves in the COVID-19 period, financial, industrial, and technology news impacts are similar to their trends in the entire period. However, the news impact curve of the services sector has diverged considerably; it is inverse U-shaped in the COVID-19 period. This implies that smaller shocks (whether negative or positive) increase volatility more than greater shocks. This result, which contradicts the finance theory, can be the result of a violation of assumptions regarding the model coefficients. However, since the other models do not show such a contradiction to the theory, the result for the services sector may also reflect a data-specific issue. Therefore, it is useful to be careful in interpreting this finding. 


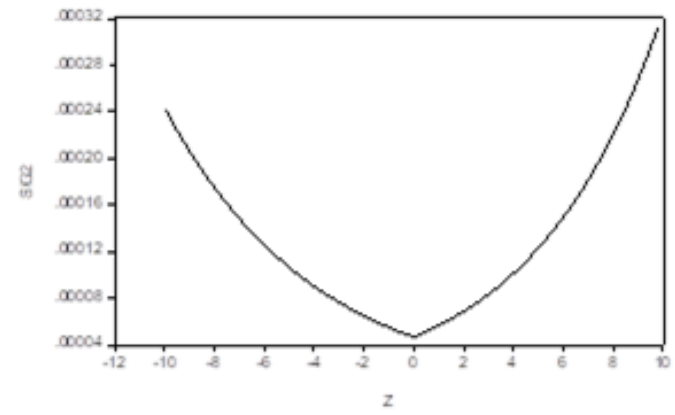

(a) Services, Entire Period

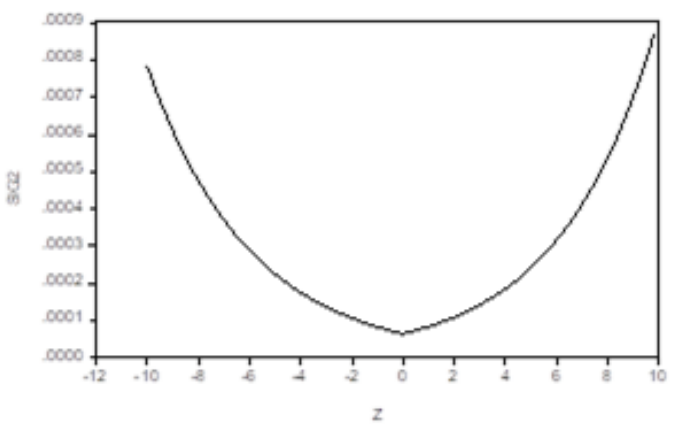

(c) Financial, Entire Period

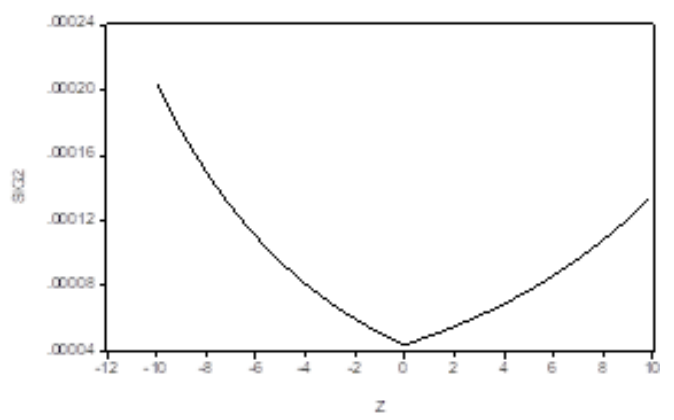

(e) Industrial, Entire Period

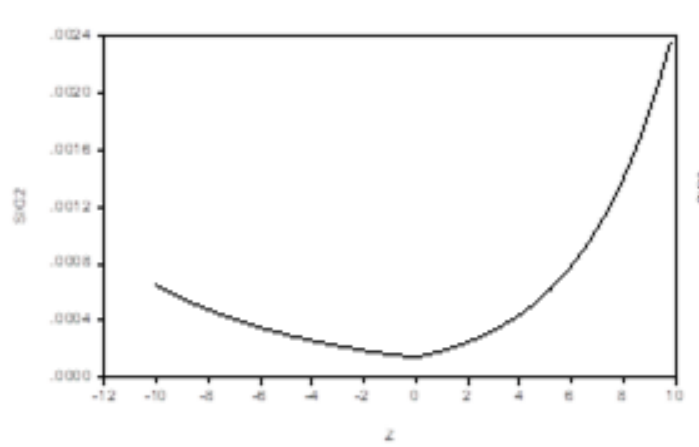

(g) Technology, Entire Period

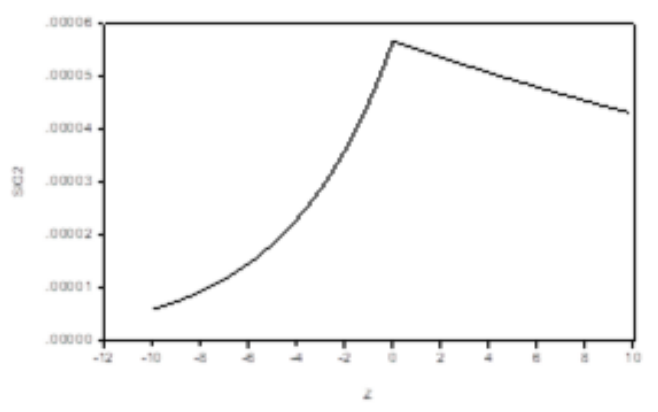

(b) Services, COVID-19 Period

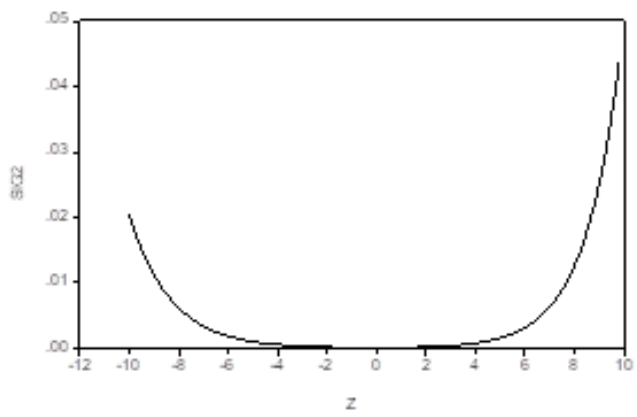

(d) Financial, COVID-19 Period

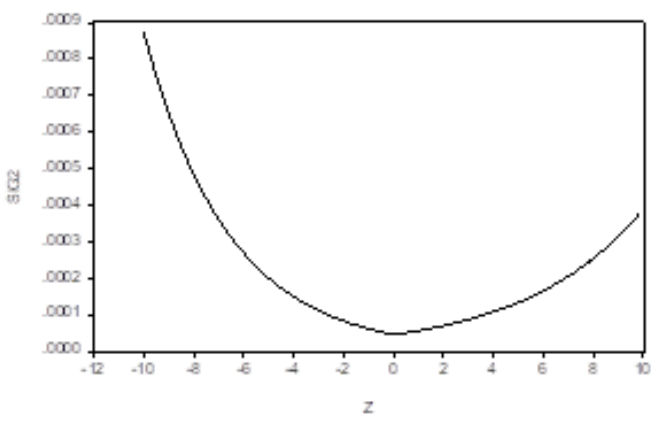

(f) Industrial, COVID-19 Period

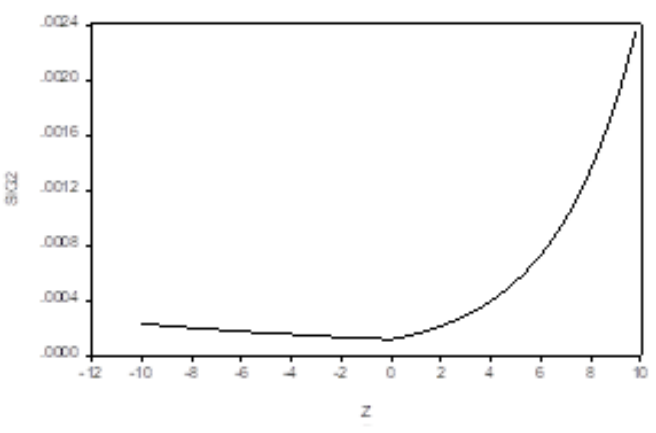

(h) Technology, COVID-19 Period

Figure 2: News Impact Curve Result 


\section{Conclusions}

With the declaration of the COVID-19 outbreak as a pandemic, significant decreases have occurred in the global financial markets. However, even if the crisis in a country affects the financial markets negatively, some sectors, such as the medical products and pharmacy sector, food sector, and video streaming sector might be positively affected by this situation. For this reason, it is important to investigate how the COVID-19 pandemic affects the sectors. In this study, it was investigated how the stock indices of the sectors were affected by the COVID-19 pandemic. The study investigates four major sectoral stock return data from Borsa Istanbul (BIST), namely the services sector, financial sector, industrial sector, and technology sector. The entire sample covers the period of 01.01.2015-20.01.2021, and the period of 12.03.2020-20.01.2021 is analyzed separately to explore the COVID-19 impacts. We analyse how the variance of the BIST sector index returns responds to good and bad news by employing an E-GARCH $(1,1)$ model to estimate the conditional variance of sectoral stock price returns by using daily data.

The results of the E-GARCH $(1,1)$ model show that negative return shocks generate more volatility than positive return shocks for the services sector returns. On the contrary, negative return shocks generate less volatility than positive return shocks for the financial, industrial, and technology sector returns. The heterogeneity of shocks in returns at the sectoral level are generally in line with the literature. The news impact curves obtained by the E-GARCH method, which allows asymmetric expectation formation processes, are compared for the entire and the COVID-19 periods. When looking at the whole sample period, the news impact curves of the services and financial sector returns are symmetrical, while the news impact curves of the industry sector and technology stocks are asymmetrical. When we look at the news impact curves in the COVID-19 period, financial, industry, and technology news impacts are similar to the whole period. However, the news impact curve of the services sector has diverged considerably. However, the theoretical basis for interpreting this finding is weak. This finding, which contradicts to the finance theory, may have resulted from a violation of the assumptions concerning the model coefficients or a data-specific situation. For this reason, we are reluctant to interpret this finding.

Within the framework of these results, financial investors can use the knowledge that the sectors' responses to good and bad news during the COVID-19 pandemic period differ. Thus, it can be said that they can evaluate their investment decisions more accurately.

\section{References}

Al-Awadhi, A. M., Alsaifi, K., Al-Awadhi, A., \& Alhammadi, S. (2020). Death and contagious infectious diseases: Impact of the COVID-19 virus on stock market returns. Journal of Behavioral and Experimental Finance, 27, 100326. doi:10.1016/j.jbef.2020.100326

Ashraf, B. N. (2020). Stock markets' reaction to COVID-19: Cases or fatalities? Research in International Business and Finance, 54, 101249. doi:10.1016/j.ribaf.2020.101249

Black, F. (1976). Studies of stock market volatility changes. In 1976 Proceedings of the American Statistical Association Bisiness and Economic Statistics Section. 
Chen, X., \& Ghysels, E. (2011). News - Good or Bad-and Its Impact on Volatility Predictions over Multiple Horizons. The Review of Financial Studies, 24(1), 46-81. doi:10.1093/rfs/hhq071

Dickey, D. A., \& Fuller, W. A. (1981). Likelihood Ratio Statistics for Autoregressive Time Series with a Unit Root. Econometrica, 49(4), 1057-1072. doi:10.2307/1912517

Elgin, C., Basbug, G., \& Yalaman, A. (2020). Economic policy responses to a pandemic: Developing the COVID-19 economic stimulus index). Covid Economics, 3, 40-53. http://www . amcham-egypt.org/bic/pdf/corona1/Covid $\% 20$ Economics $\% 20$ by $\%$ 20CEPR . pdf\#page $=44$.

Engle, R. F. (1982). Autoregressive Conditional Heteroscedasticity with Estimates of the Variance of United Kingdom Inflation. Econometrica, 50(4), 987-1007. doi: $10.2307 / 1912773$

Engle, R. F., \& Ng, V. K. (1993). Measuring and Testing the Impact of News on Volatility. The Journal of Finance, 48(5), 1749-1778. doi:10.1111/j.1540-6261.1993.tb05127.x

Ewing, B. T., Kruse, J. B., \& Thompson, M. A. (2005). Comparing the Impact of News: A Tale of Three Health Care Sectors. Journal of Business Finance $\&$ Accounting, 32(7-8), 1587-1611. doi:10.1111/j.0306-686X.2005.00641.x

Franses, P. H., Van Dijk, D., et al. (2000). Non-linear Time Series Models in Empirical Finance. Cambridge University Press.

Glosten, L. R., Jagannathan, R., \& Runkle, D. E. (1993). On the Relation between the Expected Value and the Volatility of the Nominal Excess Return on Stocks. The Journal of Finance, 48(5), 1779-1801. doi:10.1111/j.1540-6261.1993.tb05128.x

Göker, İ. E. K., Eren, B. S., \& Karaca, S. S. (2020). The Impact of the Covid19 (coronavirus) on the Borsa Istanbul Sector Index Returns: An Event Study. Gaziantep University Journal of Social Sciences, 19 (COVID-19 Special Issue), 14-41. doi:10.21547/jss.731980

Kandil Göker, I. E., Eren, B. S., \& Karaca, S. S. (2020). COVID-19 (Koronavirüs)'un Borsa İstanbul Sektör Endeks Getirileri Üzerindeki Etkisi: Bir Olay Çalışması. Gaziantep University Journal of Social Sciences, 19 (COVID-19 Special Issue), 14-41. doi: $10.21547 /$ jss. 731980

Kılıç, Y. (2020). Borsa İstanbul'da COVID-19 (Koronavirüs) Etkisi. JOEEP: Journal of Emerging Economies and Policy, 5(1), 66-77. https://dergipark.org.tr/en/pub/ joeep/issue/53777/734904.

Kwiatkowski, D., Phillips, P. C., Schmidt, P., \& Shin, Y. (1992). Testing the null hypothesis of stationarity against the alternative of a unit root: How sure are we that economic time series have a unit root? Journal of Econometrics, 54(1), 159-178. doi:10.1016/03044076(92)90104-Y 
Li, C. W., \& Li, W. K. (1996). On a double-threshold autoregressive heteroscedastic time series model. Journal of Applied Econometrics, 11(3), 253-274. doi:10.1002/(SICI)10991255(199605)11:3<253::AID-JAE393>3.0.CO;2-8

Liu, H., Manzoor, A., Wang, C., Zhang, L., \& Manzoor, Z. (2020). The COVID-19 Outbreak and Affected Countries Stock Markets Response. International Journal of Environmental Research and Public Health, 17(8), 2800. doi:10.3390/ijerph17082800

Nelson, D. B. (1991). Conditional Heteroskedasticity in Asset Returns: A New Approach. Econometrica, 59(2), 347-370. doi:10.2307/2938260

Özdemir, L. (2020). Covid-19 pandemisinin BIST sektör endeksleri üzerine asimetrik etkisi. Finans Ekonomi ve Sosyal Araştırmalar Dergisi, 5(3), 546-556. doi:10.29106/fesa. 797658

Öztürk, Ö., Şişman, M. Y., Uslu, H., \& Çıtak, F. (2020). Effect of COVID-19 outbreak on Turkish stock market: a sectoral-level analysis. Hitit University Journal of Social Sciences Institute, 13(1), 56-68. https://www.ceeol.com/search/article-detail?id=886533.

Phillips, P. C. B., \& Perron, P. (1988). Testing for a unit root in time series regression. Biometrika, 75(2), 335-346. doi:10.1093/biomet/75.2.335

Sansa, N. A. (2020). The Impact of the COVID-19 on the Financial Markets: Evidence from China and USA. Electronic Research Journal of Social Sciences and Humanities, 2(II). doi:10.2139/ssrn.3567901

Tayar, T., Gümüştekin, E., Dayan, K., \& Mandi, E. (2020). Covid-19 krizinin Türkiye'deki sektörler üzerinde etkileri: Borsa İstanbul sektör endeksleri araştırması. Yüzüncü Y $Y l$ Üniversitesi Sosyal Bilimler Enstitüsü Dergisi(Salgın Hastalıklar Özel Sayısı), 293-320. https://dergipark.org.tr/en/pub/yyusbed/issue/56115/772087.

Zakoian, J. M. (1994). Threshold heteroskedastic models. Journal of Economic Dynamics and Control, 18(5), 931-955. doi:10.1016/0165-1889(94)90039-6

Zeren, F., \& Hizarcı, A. (2020). The impact of covid-19 coronavirus on stock markets: evidence from selected countries. Muhasebe ve Finans Incelemeleri Dergisi, 3(1), 78-84. doi:10.32951/mufider.706159

Zhang, D., Hu, M., \& Ji, Q. (2020). Financial markets under the global pandemic of COVID-19. Finance Research Letters, 36, 101528. doi:10.1016/j.frl.2020.101528 